\title{
Utilizing the synchronous condenser for robust functioning of wind farm implanted electric grid
}

\author{
Famous Oghomwen Igbinovia*, Ghaeth Fandi ${ }^{*}$, Juraj Kubica ${ }^{* *}$, \\ Zdenek Muller $^{*}$, Frantisek Janicek ${ }^{* *}$, Josef Tlusty ${ }^{* * * *}$
}

\begin{abstract}
Present-day electricity grids are equipped with sophisticated devices that allow to meet various grid code requirements. These include reactive and active power controls to ensure robust functioning of the grid. Robust operation of the electricity grid entails favourable voltage and frequency profile adjustments that can be achieved through reactive and active power controls. This study presents the synchronous condenser capability of providing voltage regulation and reactive power output, and the active power possibility path of a type-3 wind machine for dynamic state conditions and voltage stability issues. Simulations carried out in the MATLAB/Simulink environment prove the efficiency of the proposed methodology.
\end{abstract}

K e y w ords: active power, reactive power, synchronous condenser, wind farm, voltage stability, power losses

\section{Introduction}

It is observed that the high impedance of a weak grid bond places a limit on the output power of a wind farm functioning at unity power factor. This shortcoming can be taken care of by adequately providing reactive power support to the grid. Even though it is feasible for wind power machines to generate the needed reactive power, this technique can markedly increase the volt-ampere (VA) rating need and consequently the cost of wind power machines and control inverters. Power system engineers in the electric-power industry have repeatedly had reactive power compensation as a concern owing to its influence on the active power transfer and on sustaining voltage levels at distinct buses and on the network security. It is noticeable that more than $90 \%$ of regional blackouts in some countries have been brought about by voltage collapse of the transmission network because of inadequate local sources of reactive power, predominantly dynamic or fast acting sources of reactive power provision like that supplied by generators, and flexible alternating current transmission system (FACTS) devices $[1,2]$. The issue of voltage collapse can be successfully resolved by the synchronous condenser (SC) supplying adequate reactive power to the grid [3-7]. It may be surprizing to mention the synchronous condenser as a new technology as it has been in use for many years. The synchronous condenser is a long-established, pre-deregulation era technology that serves as a source of reactive power compensation. Synchronous condensers can provide inertia, short-circuit power contribution, short-term overload capability, and reactive power compensation to the electricity transmission network. To provide the required functionality, new synchronous condensers can be installed in existing transmission substations or, on the other hand, retired generators can be retrofitted to synchronous condensers [8].

Apart from reactive power compensation in electricity grids, the active power is equally an issue in modern electric power grids. Power production from renewable supplies is increasing rapidly as compared with traditional fuels. Wind is the fastest growing renewable energy source [9]. As electric power production mix advances to a higher spread of wind farms, there are points on the electricity grid where stability becomes a problem. Hence, the need arises for active and reactive power regulation using wind machines for the former and the synchronous condenser technology for the latter [10]. The Type- 3 wind machines are more efficient in extracting power than other types of wind power machines [11]. The coefficients of performance of Type- 3 wind machines can be between 0.4 and $0.5[12,13]$. Hence, the doubly fed asynchronous/induction generator (DFAG/DFIG), thus a Type-3 wind machine technology, has been recommended for wind farm electricity generation.

\footnotetext{
* Department of Electrical Power Engineering, Faculty of Electrical Engineering, Czech Technical University in Prague, Czech Republic, igbinfam@fel.cvut.cz or, famousigbinovia@yahoo.co.uk, fandigha@fel.cvut.cz, zdenek.muller@fel.cvut.cz, tlusty@fel.cvut.cz, ** Institute of Power and Applied Electrical Engineering, Faculty of Electrical Engineering and Information Technology, Slovak University of Technology, Bratislava, Slovakia, juraj.kubica@stuba.sk, frantisek.janicek@stuba.sk, *** Department of Health Care Disciplines and Population Protection, Faculty of Biomedical Engineering, Czech Technical University in Prague, Sportovcu 2311, 272 01 Kladno, Czech Republic, tlusty@fbmi.cvut.cz
}

DOI: $10.2478 /$ jee-2019-0022, Print (till 2015) ISSN 1335-3632, On-line ISSN 1339-309X 


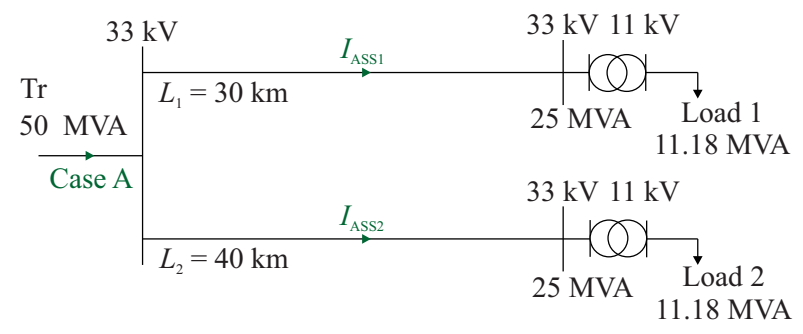

Fig. 1. Schematic diagram of the standard network

Table 1. Parameters of the MV electrical power lines

\begin{tabular}{lcc}
\hline Line number & 1 & 2 \\
\hline Positive resistance $r_{1}(\Omega / \mathrm{km})$ & 0.0922 & 0.0922 \\
Zero-sequence resistance $r_{0}(\Omega / \mathrm{km})$ & 0.312 & 0.312 \\
Positive inductance $l_{1}(\mathrm{mH} / \mathrm{km})$ & 0.61 & 0.61 \\
Zero-sequence inductance $l_{0}(\mathrm{mH} / \mathrm{km})$ & 2.83 & 2.83 \\
Positive capacitance $c_{1}(\mathrm{nF} / \mathrm{km})$ & 11.3 & 11.3 \\
Zero-sequence capacitance $c_{0}(\mathrm{nF} / \mathrm{km})$ & 5.01 & 5.01 \\
Frequency $f_{\mathrm{n}}(\mathrm{Hz})$ & 50 & 50 \\
Length $(\mathrm{km})$ & 30 & 40 \\
Phase resistance $R_{1}(\Omega)$ & 2.77 & 3.69 \\
Phase inductive reactance $X_{1}(\Omega)$ & 5.75 & 7.67 \\
Phase susceptance $B(\mu \mathrm{S})$ & 53.4 & 71.2 \\
\hline
\end{tabular}

Table 2. Parameters of the three-phase $33 / 11 \mathrm{kV}$ tran

\begin{tabular}{lcc}
\hline Transformer 1, 2 & HV winding & LV winding \\
\hline Connection type & D11 & Yg \\
$V(\mathrm{~V})$ & 33 & 11 \\
$R(\Omega)$ & 0.157 & 0.0166 \\
$L(\mathrm{H})$ & 0.00581 & 0.00062 \\
\hline $\mathrm{f}=50 \mathrm{HZ}$, Nominal power $25 \mathrm{MVA}$ \\
Magnitization resistance $65.3 \mathrm{k} \Omega$ \\
\multicolumn{2}{l}{ Magnetization inductance $208 \mathrm{H}$}
\end{tabular}

The active power priority mode for Type- 3 wind power machines is recommended in this work. This is to allow wind farms to produce adequate active power during normal operating conditions. In this work, the Type-3 wind machine is set in the active power mode, while the reactive power path of the wind machine is decoupled. The DFAG/DFIG-based wind machines are extensively used in existing wind farms [14], where each DFAG/DFIG unit is linked to the collector network directly through its stator, while its rotor is connected to the grid through a back-to-back converter scheme. The converter scheme permits independent control of the active power delivery to the electricity grid via the Type-3 DFAG/DFIG-based wind farm and the reactive power exchange with the synchronous condenser. The rotor-side converter (RSC) of the wind machine often controls the stator power flow based on a smaller percentage of power injected into the rotor circuit of the suggested scheme. For this reason, the back-to-back converter is in most cases rated between 30 and $40 \%$ of the wind machine rated power. The reduced size of the Type-3 machine converter implies a lower cost of both the converter and its filter. Additionally, it minimizes converter losses as compared with the full rated converter wind energy technology.

Owing to the utilization of the synchronous condenser in electricity networks, additional inertia and shortcircuit current could be made available, which could in turn enhance the functioning of the wind farm implanted grid. However, the synchronous condenser and wind machines are adopted for reactive and active power regulation. An obvious question that arises and needs to be answered by this research is the point or position, where the synchronous condenser and wind farm should be deployed. This query still has not been answered in existing research works. Therefore, this research work develops a methodology to evaluate the required position or point to locate the synchronous condenser and the wind farm on the electricity grid. To examine the effectiveness of the proposed methodology, it is applied to a medium voltage (MV) power grid with proliferated wind production. The reactive and active power control strategies and encountered issues are discussed including the methodology, measurements and simulation results from study cases. The results of this research will help in advising electricity utility providers to make better use of new synchronous condensers and retired retrofitted generators to provide the required functionality for the electricity grid, which will finally prepare the way for further integration of wind power machines and other renewables in presenttime power systems.

\section{Modelling of the standard power system and its elements}

In this research work, a $50 \mathrm{~Hz}, 33 \mathrm{kV}$ grid and $50 \mathrm{MVA}$ substation base on a standard utility medium voltage (MV) transmission power system is presented as a standard or reference case as shown in Fig. 1.

There are two load points, each totaling 11.18 MVA. The MV distribution system has two $33 \mathrm{kV}$ power lines L1 and L2 of lengths $30 \mathrm{~km}$ and $40 \mathrm{~km}$ connected to it. The lines interconnect different parts of the $11 \mathrm{kV}$ consumer network to facilitate power exchange between the 


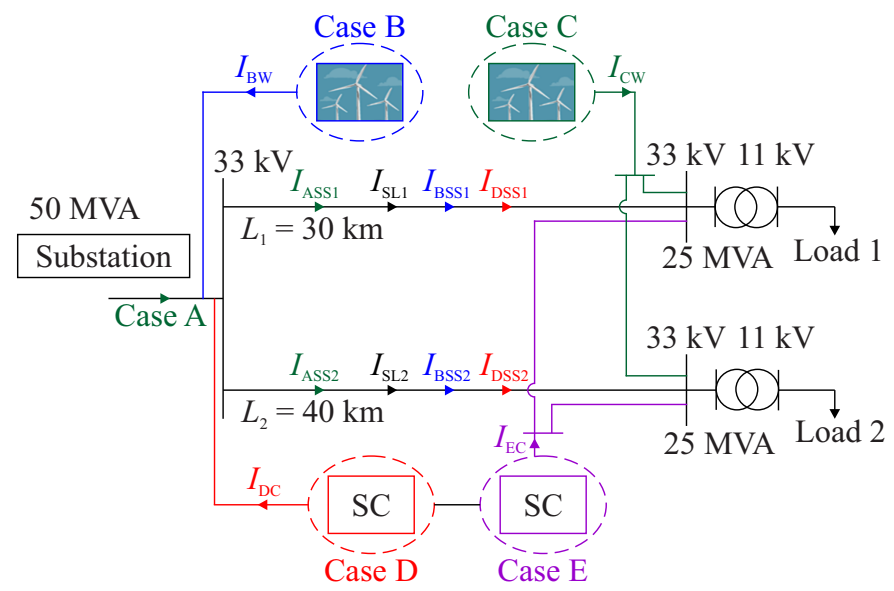

Fig. 2. The proposed scheme with installed synchronous condenser and wind plants

Table 3. Measured values of the load

\begin{tabular}{lc}
\hline Active power $P_{L}(\mathrm{MW})$ & 10 \\
Reactive power $Q_{L}(\mathrm{MVAr})$ & 5 \\
Apparent power $S_{L}(\mathrm{MVA})$ & 11.2 \\
$\cos \phi$ & 0.894 \\
\hline $\mathrm{f}=50 \mathrm{HZ}$, Consumer voltage $11 \mathrm{kV}$
\end{tabular}

loads. The installed capacity at the consumer end transformer substation is 25 MVA. Note that all transmission lines are modelled using pi-model.

Specifications of the power lines are given in Table 1 . The rated positive resistances $r_{1}(\Omega / \mathrm{km})$, zero-sequence resistances $r_{0}(\Omega / \mathrm{km})$, positive inductances $l_{1}(\mathrm{mH} / \mathrm{km})$, zero-sequence inductances $l_{0}(\mathrm{mH} / \mathrm{km})$, zero-sequence capacitances $c_{0}(\mathrm{nF} / \mathrm{km})$, positive capacitances $c_{1}(\mathrm{nF} / \mathrm{km})$, and frequency $f_{\mathrm{n}}(\mathrm{Hz})$ are the same for the two lines. The lines lengths $(\mathrm{km})$, phase resistances $R_{1}(\Omega)$, phase inductive reactances $X_{1}(\Omega)$, and phase susceptances $B(\mu \mathrm{S})$ differ as presented.

The MV power lines supply $33 \mathrm{kV} / 11 \mathrm{kV}$ transformers rated at 25 MVA. As shown in Table 2, the frequency, nominal power, magnetization resistance and magnetization inductance are the same for the two transformers.

The 25 MVA transformer at the busbar end supplies the consumer load at a level of $11 \mathrm{kV}$. The recorded values of the load are shown in Table 3. The frequency and the load voltage are same for both loads, but the active power, reactive power, apparent power and the power factor $(\cos \pi)$ differ for single loads.

Measurements of the source and load powers and voltages (thus of power losses and voltage drops) for the two lines were taken in the reference case, this is shown in Table 4. Subscripts s and $r$ denote the sending and receiving ends of the lines, respectively.

\section{Methodology}

A 3.125 MVA synchronous condenser has been used in this research work. It is a round-rotor type machine, modelled in detail with its excitation systems. It is a modified version of the built-in model by MATLAB/Simulink. The setting allows feeding the entire power system with adequate reactive power needs. This type of control strategy focuses on reactive power injection to the local bus or substation, depending on the position or point of connection. The synchronous condenser is investigated for reactive power production aiding the wind farm during dynamic situations.

A wind farm rated $9 \mathrm{MW}$ based on Type-3 wind machine with a power factor rating of 0.9 is used in this work. The DFIG model used in this study is a modified version of the built-in model by MATLAB/Simulink [15]. It consists of a wound rotor induction generator and $\mathrm{C} / \mathrm{DC} / \mathrm{AC} / \mathrm{IGBT}$-based pulse-width modulation (PWM) converter. PWM converters provide a compact solution for converting current into a digital pulse width modulated signal, a reference voltage is made available on the PWM output. It is also equipped with a pitch control system and it is based on a doubly fed induction generator using back-to-back PWM converters. The generator stator is directly linked to the electric-power grid, whereas the rotor is joined to the electricity grid through an $\mathrm{AC} / \mathrm{DC} / \mathrm{AC}$ converter and slip rings. The converter consists of the rotor-side converter (RSC), and of the

Table 4. Measured parameters of the benchmark commercial three-phase lines

\begin{tabular}{lccccccc}
\hline Line & $P_{s}(\mathrm{MW})$ & $P_{r}(\mathrm{MW})$ & $Q_{s}(\mathrm{MVAr})$ & $Q_{r}(\mathrm{MVAr})$ & $U_{s}(\mathrm{kV})$ & $U_{r}(\mathrm{kV})$ & $\Delta P \mathrm{MW})$ \\
1 & 8.82 & 8.55 & 5.09 & 4.63 & 32.6 & 31.0 & 0.271 \\
2 & 8.62 & 8.27 & 5.06 & 4.48 & 32.6 & 30.4 & 0.350 \\
\hline
\end{tabular}




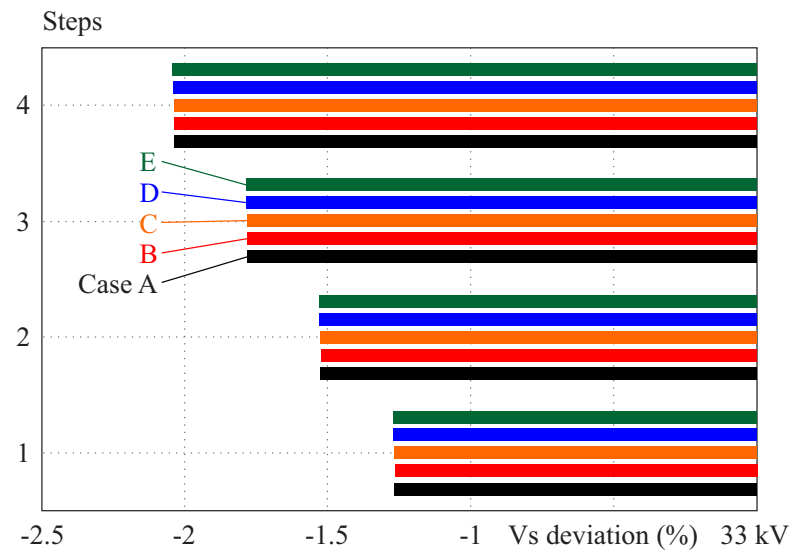

Fig. 3. Percentage of source voltage deviation from the nominal voltage of $33 \mathrm{kv}$ for different steps of cases A, B, C, D and E

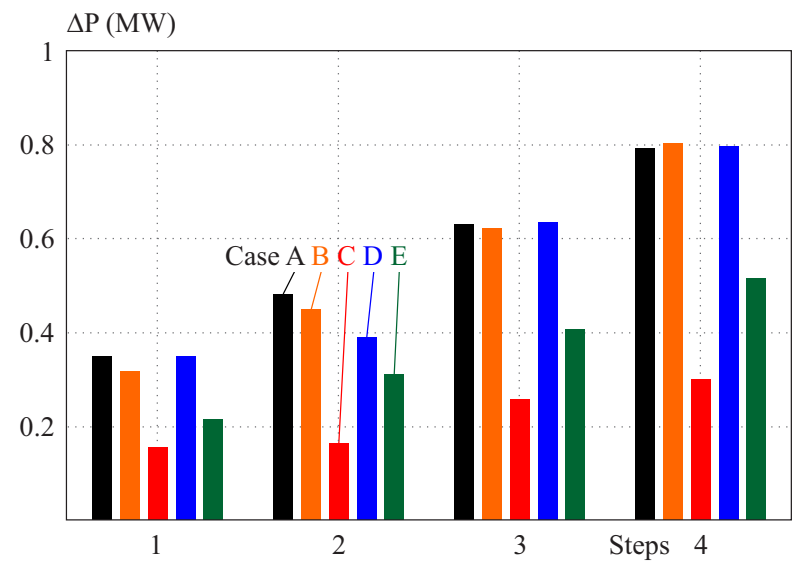

Fig. 5. Power losses for different steps of cases A, B, C, D and E

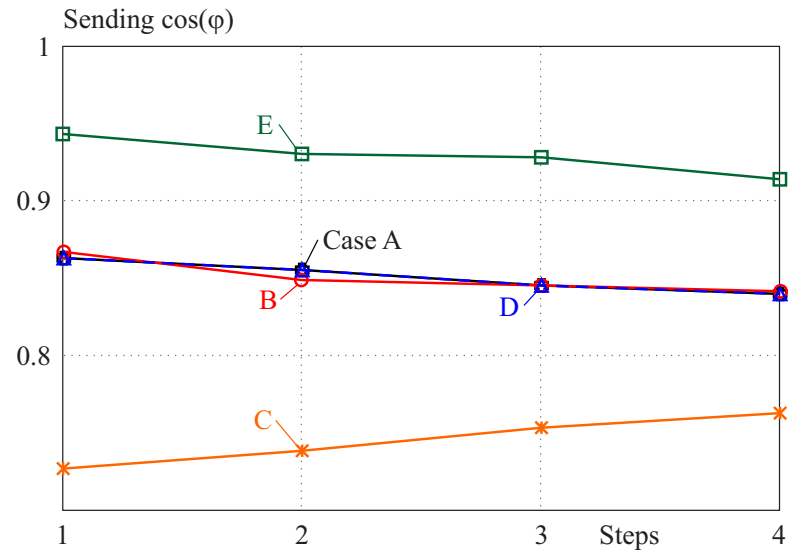

Fig. 7. Sending power factor for different steps of Cases A, B, C, $\mathrm{D}$ and

grid-side converter (GSC). A capacitor coupling the two converters acts as a DC voltage source (DC bus). Active power is generated by pre-defined power-speed characteristic. The DFIG model is deemed suitable for dynamic stability studies. In a DFIG the active power can be produced and injected into the electric-power grid by utilizing its $\mathrm{AC} / \mathrm{DC} / \mathrm{AC}$ converter system which contains

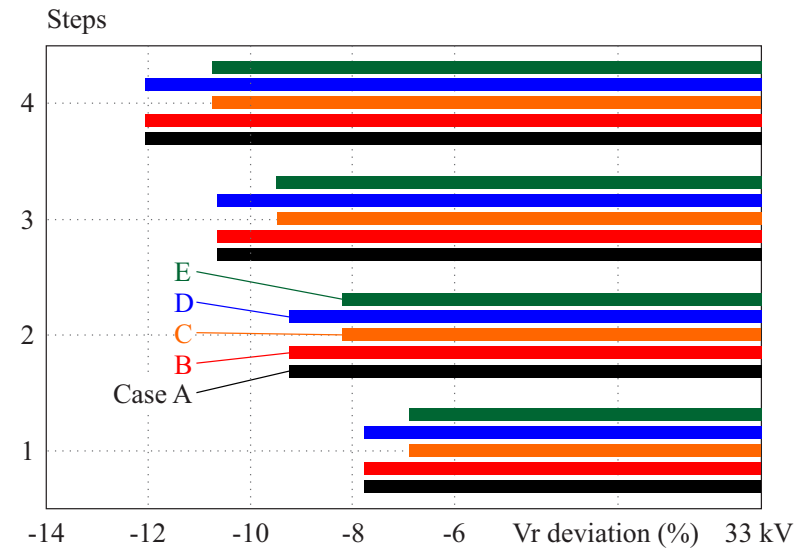

Fig. 4. Percentage of load voltage deviation from the nominal voltage of $33 \mathrm{kV}$ for different steps of cases $\mathrm{A}, \mathrm{B}, \mathrm{C}, \mathrm{D}$ and $\mathrm{E}$

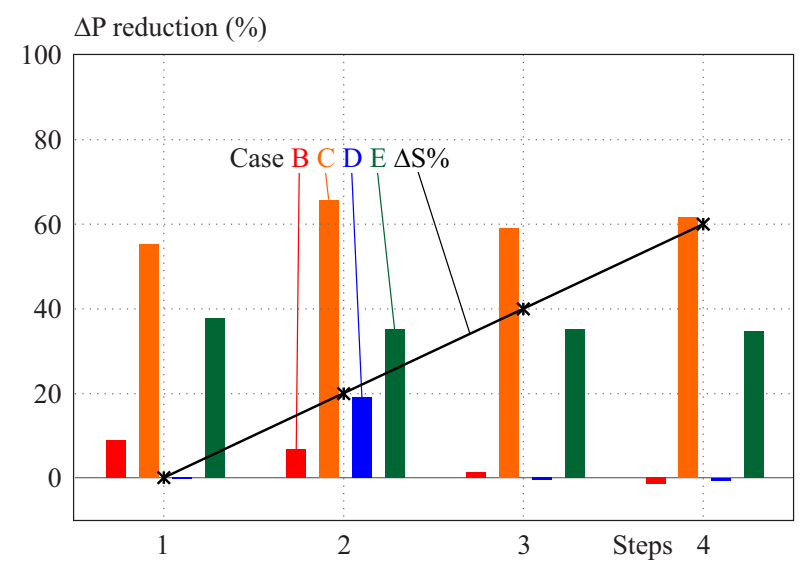

Fig. 6. Percentage of power losses reduction for different steps of cases B, C, D and E compared with case A

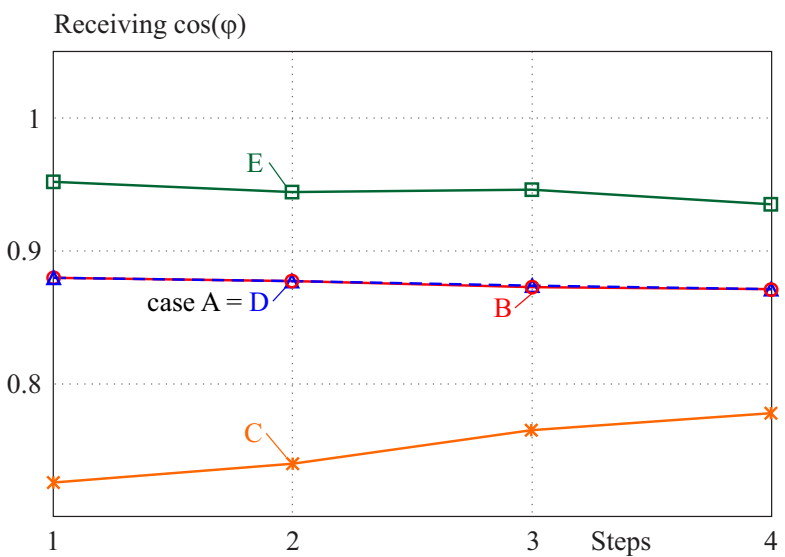

Fig. 8. Receiving power factor for different steps of Cases A, B, C, $\mathrm{D}$ and

dq-current regulators ( $d$ stands for the d-axis and $q$ for the q-axis). Methodically, by influencing or controlling the DFIG equations and steering the machine characteristic relations between flux, voltage, current and so on, one gets active power related equations (note here that the reactive power is decoupled), enabling production and injection of active power only from the wind farm. The 
DFIG model utilized for this study employs a typical vector control scheme, where the active power is controlled by regulating the rotor q-axis current and the pitch angle. All power regulators use proportional-integral (PI) controllers [16-22].

\section{Analysis with installed synchronous condenser and wind plants}

We have designed a MATLAB/Simulink model with different positioning of the synchronous condenser and the wind farm. Five cases have been considered A, B, $\mathrm{C}, \mathrm{D}$ and $\mathrm{E}$, with the positions of the synchronous condenser and wind power plants altered in each case. Case A is the standard or reference case as detailed in Section 2. Case B is a wind farm rated $9 \mathrm{MW}$ connected to the grid at the busbar of the 50 MVA main substation. Case $\mathrm{C}$ is the situation, when the wind farm rated $9 \mathrm{MW}$ is connected to the grid at the busbar close to the consumer loads of the network through two step-down transformers. The consumer load bus system is connected to the larger electricity grid and the main substation through a bus tie. The larger medium voltage grid is modelled as an equivalent source with a $33 \mathrm{kV}$ three-phase voltage source in series with an RL-impedance with a short-circuit capacity of 50 MVA. In case D there is a 3.125 MVA synchronous condenser installed at the 50 MVA main substation bus. Case E is a 3.125 MVA synchronous condenser connected to the electricity grid at the consumer load busbar through two step-down transformers each rated 25 MVA. The synchronous condenser is modelled in detail with its excitation systems. All transmission lines of the proposed scheme are modelled using pi-model. Details on modelling the system were published in [10,23].

Figure 2 shows the scheme with installed synchronous condensers and wind farms. Two performance criteria are used: first the synchronous condenser capability to produce reactive power, and second the wind farm active power generation ability. Furthermore, both the wind farms and the synchronous condensers are connected to the grid by changing their positions. The Type-3 DFIG wind machines are operated in an active power regulation mode such that its reactive power regulation mode is decoupled. The results with the synchronous condenser installed and the Type- 3 wind machine farms connected to the grid are compared with that of case A.

Four monitored steps values were obtained. The first step is the standard or reference case value of loads, while steps 2 to 4 are increased by $20 \%$ in each step.

Figure 3 shows that the source voltage deviation from the nominal voltage of $33 \mathrm{kV}$ has the same value for all cases. It should be noted that the source voltage deviation increases as we move from step 1 to 4 . Positions of the wind farm or synchronous condenser do not have any effect on the source voltage deviation. The percentage of the load voltage deviation from the nominal voltage of $33 \mathrm{kV}$ for different steps of case A, B, C, D and E is plotted in Fig. 4. The load voltage deviation decreased by a few percent in cases $\mathrm{C}$ and E. Results for cases B and D are the same. The result for reference case $\mathrm{A}$ is also the same with cases B and D.

When the wind farm or synchronous condenser is joined to the beginning of the transmission lines, the power losses reduce slightly, but when the wind farm or synchronous condenser were installed to the end of the transmission lines, power losses are reduced markedly. Note that the effect of the wind farm is much stronger due to its nominal power $9 \mathrm{MVA}$. The nominal power of the synchronous condenser is 3.125 MVA. The results for the power losses are presented in Fig. 5 and 6 .

Figure $\mathrm{t}$ and 8 report the source power factor values recorded for cases $\mathrm{A}$ to $\mathrm{E}$. No remarkable changes were seen in cases B and D, this also applies to the reference case A. The observed source power factor for case C decreases from about 0.85 to 0.75 , while that for case $\mathrm{E}$ increases to about 0.95 . Figure 9 is a graphical presentation of the load end power factor values. The power factors for cases A, B and D are steady because of the wind farm and synchronous condenser installed to the 50 MVA main substation busbar. Hence, the changes in the power flow through the transmission lines are very small. When considering case $\mathrm{C}$, the source power factor decreases owing to the wind farm connected to the end of the transmission line busbars, therefore the active power flowing through the transmission lines becomes smaller, thereby leading to a decrease in the power factor values. Also, taking into consideration case $\mathrm{E}$, the source power factor results is seen to increase owing to the synchronous condenser installed at the end of the $33 \mathrm{kV}$ transmission lines busbar connected to the two step-down transformers. For this reason, the reactive power flowing through the transmission lines becomes lower, bringing about an increase in the value of the power factor.

The percentage of voltage drop reduction for different steps of all the cases is depicted in Fig. 9. The voltage drop decreases only in cases $\mathrm{C}$ and $\mathrm{E}$ (the decrease in voltage drop is $12 \%$ ). This suggests that the voltage drop could only be reduced, when the wind farm or synchronous condenser is coupled to the end of the $33 \mathrm{kV}$ transmission lines close to the consumer substation. Note here that the percentage of voltage drop reduction is the same for all the steps observed.

\section{Conclusion}

A purposely developed simulation model based on the proposed methodology was applied to a variety of cases involving active power control by wind power plants and reactive power control using the synchronous condenser, and effective positioning of both the wind plants and the synchronous condensers. The authors have shown that wind power plants and the synchronous condenser can play a great role in reducing the power losses and voltage drop in modern power systems. Additionally, the effect 


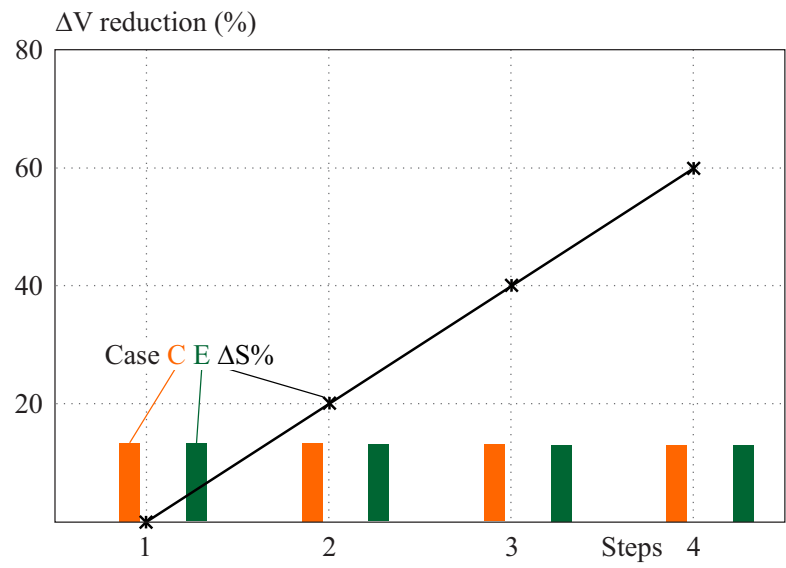

Fig. 9. Percentage of voltage drop reduction for different steps of cases B, C, D and E compared with case

of position and power capacity, when wind plants or synchronous condensers are joined to the end of transmission lines, brought about a higher reduction in power losses in the proposed scheme because the power flow through the transmission lines is reduced or lowered. It was also observed that when the power capacity is high, power losses are drastically reduced. The presented work opens a variety of opportunities to utilize new or retrofitted synchronous condensers for further advanced research in future work. Although being an old technology, the synchronous condenser remains an interesting topic for future work. Moreover, the synchronous condenser can be used for studies related to reactive power, power losses and voltage control.

\section{Acknowledgements}

This work was supported by the Grant Agency of the Czech Technical University in Prague, (grant No. SGS17/181/OHK3/3T/13).

\section{REFERENCES}

[1] US Canadian Power System Outage Task Force, "Interim Report Causes of the November 14 Blackout in the United States and Canada", pp. 71, 2003.

[2] F. O. Igbinovia, G. Fandi, J. Svec, Z. Müller, and J. Tlusty, "Comparative Review of Reactive Power Compensation Technologies", IEEE 16th International Scientific Conference on Electric Power Engineering (EPE), Kouty nad Desnou, pp. 2-7, 2015.

[3] F. O. Igbinovia, G. Fandi, Z. M'uller, J. Svec, and J. Tlusty, "Cost Implication Reactive Power Generating Potential of the Synchronous Condenser", IEEE 2nd International Conference on Intelligent Green Building Smart Grid (IGBSG) Prague, pp. 1-6, 2016.

[4] F. O. Igbinovia, G. Fandi, Z. M'uller, J. Svec, and J. Tlusty, "Optimal Location of the Synchronous Condenser in Electric-Power System Networks", IEEE 17th International Scientific Conference on Electric Power Engineering (EPE) Prague, pp. 1-6, 2016.

[5] M. Ross and S. Kalsi, "Applications of Superconducting Synchronous Condensers in Wind Power Integration", IEEE PES Transmission Distribution Conference Exhibition Dallas, pp. 272-277, 2006.
[6] F. O. Igbinovia, G. Fandi, Z. M'uller, and J. Tlusty, "Progressive Usage of the Synchronous Machine in Electrical Power Systems", Indian Journal of Engineering, vol. 15, pp. 117-126, 2018.

[7] F. O. Igbinovia, G. Fandi, Z. M'uller, and J. Tlusty, "Reputation of the Synchronous Condenser Technology in Modern Power Grid" Proceedings of the 11th International Conference on Power System Technology (POWERCON) Guangzhou, pp. 2108-2115, 2018.

[8] N. Masood, R. Yan, T. K. Saha, and S. Bartlett, "Post-Retirement Utilisation of Synchronous Generators to Enhance Security Performances in a Wind Dominated Power System", IET Generation Transmission \& Distribution vol. 10, no. 13, pp. 3314-3321, 2016.

[9] Energy Dept, Reports: US [Online], http://energy.gov, 2013,

[10] F. O. Igbinovia, G. Fandi, I. Ahmad, Z. Müller, and J. Tlusty, "Modeling Simulation of the Anticipated Effects of the Synchronous Condenser on an Electric-Power Network with Participating Wind Plants", Sustainability vol. 10, no. 12, 4834, 2018.

[11] S. Heier, "Grid Integration of Wind Energy Conversion Systems", 2nd ed, John Wiley \& Sons 2006.

12] J. Dai, D. Liu, L. Wen, and X. Long, "Research on Power Coefficient of Wind Turbines based on SCADA Data", Renewable Energy vol. 86, pp. 206-215, 2016.

[13] A. Tummala, R. K. Velamati, D. K. Sinha, V. Indrajac, and V. H. Krishnad, "A Review on Small Scale Wind Turbines", Renewable Sustainable Energy Reviews vol 56, pp. 1351-1371, 2016.

[14] J. Lopez, E. Gubia, E. Olea, J. Ruiz, and L. Marroyo, "Ride through of Wind Turbines with Doubly Fed Induction Generator under Symmetrical Voltage Dips", IEEE Transactions on Industrial Electronics vol. 56, no. 10, pp. 4246-4254, 2009.

[15] S. A. Eisa, W. Stone, and W. K. Wedeward, "Mathematical Modeling, Stability, Bifurcation Analysis", IEEE Ninth Annual Green Technologies Conference (GreenTech) Denver, pp. 334-341, 2017.

[16] N. W. Miller, J. J. Sanchez-Gasca, W. W. Price, and R. W. Delmerico, "Dynamic Modeling of GE 1.5 and 3.6 MW Wind Turbine-Generators for Stability Simulations", IEEE Power Engineering Society General Meeting Toronto, pp. 1977-1983, 2003.

[17] R. Pena, J. C. Clare, and G. M. Asher, "Doubly Fed Induction Generator using Back-to-Back PWM Converters its Application to Variable-Speed Wind-Energy Generation", IEE Proceedings-Electric Power Applications vol. 143, no. 3, pp. 231-241, 1996.

18] L. Xu and P. Cartwright, "Direct Active Reactive Power Control of DFIG for Wind Energy Generation", IEEE Transactions on energy conversion vol. 21, no. 3, pp. 750-758, 2006.

19] B. C. Rabelo, W. Hofmann, J. L. da Silva, R. G. de Oliveira, and S. R. Silva, "Reactive Power Control Design in Doubly Fed Induction Generators for Wind Turbines", IEEE Transactions on Industrial Electronics vol. 56, no. 10, pp. 4154-4162, 2009.

[20] E. Tremblay, S. Atayde, and A. Chandra, "Comparative Study of Control Strategies for the Doubly Fed Induction Generator in Wind Energy Conversion Systems: A DSP-based Implementation Approach", IEEE Transactions on sustainable energy vol. 2 , no. 3, pp. 288-299, 2011.

[21] S. Li, T. A. Haskew, K. A. Williams, and R. P. Swatloski, "Control of DFIG Wind Turbine with Direct-Current Vector Control Configuration", IEEE transactions on Sustainable Energy vol. 3, no. 1, pp. 1-11, 2012.

22] H. T. Le and S. Santoso, "Operating Compressed-Air Energy Storage as Dynamic Reactive Compensator for Stabilising Wind Farms under Grid Fault Conditions", IET Renewable Power Generation vol. 7, no. 6, pp. 717-726, 2013.

[23] G. Fandi, I. Ahmad, F. O. Igbinovia, Z. Müller, J. Tlusty, and V. Krepl, "Voltage Regulation Power Loss Minimization in Radial 
Distribution Systems via Reactive Power Injection Distributed Generation Unit Placement", Energies vol. 11, p. 1399, 2018.

Received 11 January 2019

Famous O. Igbinovia received his Bachelor of Engineering (BEng) degree in electrical/electronic engineering from Ambrose Alli University, Ekpoma, Nigeria, the Master of Engineering (MEng) degree in power and machines from the University of Benin, Benin City, Nigeria, and the Master of Science (MSc) degree in business administration from the Czech University of Life Sciences in Prague, Czech Republic. He is currently a doctorate $(\mathrm{PhD})$ candidate in the Department of Electrical Power Engineering at Czech Technical University (CTU) in Prague, Czech Republic. His research interests are renewable energy systems, control of electrical power systems, power quality, distributed and dispersed generation sources in distribution systems, electricity market and hybrid simulation of power systems. He is a member of the Institute of Electrical and Electronics Engineers (IEEE).

Ghaeth Fandi was born in Latakia, Syria. He holds a degree in electrical engineering from the University of Tishreen, Latakia, Syria, a masters degree in renewable energy from the same university and a PhD degree in power engineering from the Czech Technical University (CTU) in Prague, Czech Republic. He works with the Department of Electrical Power Engineering at CTU in Prague. His research interest is in the areas of renewable energy dispersed generation sources in distribution system. Other activities include hybrid simulation of power systems, power quality and research of control of electrical power systems. He is a member of the Institute of Electrical and Electronics Engineers (IEEE).

Juraj Kubica was born in Bratislava in 1982. He received his masters degree in materials sciences from the Slovak University of Technology, Bratislava, in 2007. In 2013 he received his $\mathrm{PhD}$ degree in power engineering from the Slovak University of Technology. He works at the Institute of Power and Applied Electrical Engineering, Faculty of Electrical Engineering and Information Technology, Slovak University of Technology in Bratislava. He also works as a senior advisor at the Office of the Deputy Prime Minister for Investments and Informatisation of Slovakia and he has been involved in the scheme for the support of small distributed generation power sources. His research interests include decentralised power generation in renewable energy sources, mainly from biomass and solar cells.

Zděnek Müller graduated from the Czech Technical University in Prague, Faculty of Electrical Engineering in 2006. He received his $\mathrm{PhD}$ degree in 2012 from the same university. Since 2006 he worked as technician and later as assistant professor at CTU in Prague. In 2015 he was appointed associate professor level, since 2016 he has worked as head of the Department of Electrical Power Engineering at CTU in Prague. He is senior member of the IEEE. His research interests are in the areas of intelligent transmission and distribution systems (wide area monitoring, protection and control), smart grids, smart metering and new approaches to asset management).

František Janíček was born in 1954. He graduated from the Faculty of Electrical Engineering of the Slovak University of Technology in 1979. In 1984, he obtained the PhD degree in power engineering and in 1999 he was appointed Professor. He has authored or co-authored 13 university textbooks and lecture books, 4 specialist monographs, more than 50 articles in journals and more than 100 presentations at international scientific conferences. He has put over 80 technical projects into practice. He is one of the co-founders of the internet-based information and education project INFELEN (information on power engineering). He is a member of the Slovak WEC SR committee, a statutory representative of the EE Association (8 organizations) and member of scientific boards of several universities in Slovakia.

Josef Tlustý is currently Professor of electrical power engineering at the Czech Technical University in Prague, Czech Republic. In 1971 he obtained a masters degree in power engineering (energy utilisation) from the Czech Technical University in Prague and in 1978 the $\mathrm{PhD}$ degree in power engineering from the same university. His research interests include renewable energy systems, control and protection of electrical power systems, distributed generation sources in distribution systems, power voltage quality in electrical power systems and the use of flexible alternating current transmission systems (FACTS) in electrical networks. He is a fellow of the Institute of Electrical and Electronics Engineers (IEEE). 